\title{
SYNTHESIS OF CHEMICALLY MODIFIED CARBON EMBEDDED SILICA AND ZEOLITE FROM RICE HUSK TO ADSORB CRYSTAL VIOLET DYE FROM AQUEOUS SOLUTION
}

\author{
ISLAM, T. ${ }^{1,2}-$ LIU, J. ${ }^{1,3}-$ SHEN, G. ${ }^{3}-$ YE, T. ${ }^{1}-$ PENG, C. ${ }^{1,3^{*}}$ \\ ${ }^{1}$ The Key Lab of Marine Environmental Science and Ecology, Ministry of Education, Ocean \\ University of China, 266100 Qingdao, China \\ ${ }^{2}$ Department of Agricultural Construction and Environmental Engineering, Sylhet Agricultural \\ University, Sylhet-3100, Bangladesh \\ ${ }^{3}$ School of Environment and Chemical Engineering, Zhaoqing University \\ 526061 Zhaoqing, China \\ *Corresponding author \\ e-mail: pcs005@ouc.edu.cn; phone: +86-532-6678-2011; fax: +86-532-6678-2011 \\ (Received 20 $0^{\text {th }}$ Mar 2018; accepted $25^{\text {th }}$ May 2018)
}

\begin{abstract}
Toxic dyes contaminated aqueous solutions discharged from different industries should be treated before releasing to the environment. In the present study adsorbents manufactured from an easily available waste rice husk (RH) has been used to treat dyes contaminated water. Hereby, two adsorbents, carbon embedded silica (CES) and rice husk ash (RHA) mediated zeolite (Z-RHA) have been synthesized from rice husk by chemical modification, and a comparative study has been performed for decontaminating crystal violet (CV) dye laden aqueous solution. Characterization of the manufactured RHA, CES and Z-RHA has been done by using several techniques like Fourier transform infrared spectroscopy (FTIR), X-ray diffraction (XRD), Scanning electron microscope (SEM), Energy dispersive X-ray (EDX) and Brunauer-Emmett-Teller (BET). The specific surface area for RHA, CES and Z-RHA was $28 \mathrm{~m}^{2} / \mathrm{g}, 110 \mathrm{~m}^{2} / \mathrm{g}$ and $122 \mathrm{~m}^{2} / \mathrm{g}$ respectively. Additionally, batch experiments have been performed to evaluate the effect of different parameters like initial concentrations of the adsorbate, initial $\mathrm{pH}$, adsorbent dosages and contact time. The adsorption capacity of the CES and Z-RHA is $18.75 \mathrm{mg} / \mathrm{g}$ and $19.28 \mathrm{mg} / \mathrm{g}$ respectively, which are satisfactorily higher than the adsorption capacity of their parent material RHA $(8.3 \mathrm{mg} / \mathrm{g})$. In the optimization study, the maximum adsorption has been found at the initial concentration of $100 \mathrm{mg} / \mathrm{l}$ of the dye, solution $\mathrm{pH} 8$, adsorbent dosages $0.6 \mathrm{mg} / 50 \mathrm{ml}$ and contact time 10 min. This study stated that the chemically modified adsorbents manufactured from RHA can be an easy solution to remove $\mathrm{CV}$ dye from wastewater.
\end{abstract}

Keywords: toxic dye removal, polluted water, carbon embedded silica, modified rice husk, zeolite

\section{Introduction}

Nowadays, synthetic dyes are used in different industries like the garment dye industries, textile, plastic, leather, paper, food, mineral processing and cosmetic industries (Dalaran et al., 2011; Kumari et al., 2017). There are more than 10 thousand dyes that are currently used in different industries and the annual production of the dyes all over the world is around 280 thousand tons, which is a huge amount (Mass and Chaudhari, 2005). Alarming amount of dyes are being released into the environment from these industries each year. A small amount of dyes can cause serious pollution of water due to their harmful characteristics such as high visibility, low biodegradability and toxicity (Arenas et al., 2017; O'Neill et al., 1999). Dye-contaminated water can be carcinogenic as well as mutagenic due to their obstruction of light penetration into water which inhibits the photosynthesis activity of aquatic biota (Vakili et al., 2014). 
Consequently those dyes can have harmful effects on human beings through aquatic animals and alimentary chain (Secula et al., 2011). Removal of dyes is a great concern not only to protect the environment but also to make it safe for the human health. Among different types of toxic dyes crystal violet $(\mathrm{CV})$ represents one of the mostly used cationic dyes in different industries. The characteristics of the CV dyes are shown in Table 1. Cationic dyes are colored organic base salts and they have no water solubilizing agent. Due to these characteristics the cationic dyes are more toxic than the anionic dyes (Loqman et al., 2017; Hao et al., 2000). CV is also known as hexamethyl pararosaniline chloride. There are a lot of established techniques for removing toxic dyes from wastewater approved by different studies such as electrocoagulation, electrochemical oxidation and advanced oxidation process (Arenas et al., 2017). Moreover, the physical treatment like adsorption is very much useful technique to remove toxic compounds from wastewater, if the adsorbents are readily available and cost effective (Banerjee et al., 2017; Lakshmi et al., 2009). There are lots of studies on the activated carbon from different available cheap materials like coconut husk, coconut shell, bamboo ash etc. to reduce toxicity from water or wastewater (Arenas et al., 2017; Yadav et al., 2015; Zhang et al., 2011; Yadanaparthi et al., 2009; Xu et al., 2009). In this study we are using the rice husk ash (RHA) to make zeolite (Z-RHA) and carbon embedded silica (CES) to remove the toxic dye CV from the wastewater. Rice husk $(\mathrm{RH})$ is an easily available material with no price. The amount of the $\mathrm{RH}$ is assumed to be approximately twenty percent of the gross weight of grain produced (Arenas et al., 2017). In the disposal point of view, the end material of paddy is very much harmful for environment. RHA has higher efficiency to remove either biodegradable or nonbiodegradable toxic pollutants from wastewater due to its highly porous surface and large surface area (Naiya et al., 2009). On the other hand, RHA mainly contained $\mathrm{SiO}_{2}$ which is very much useful to remove different kinds of heavy metal and dyes after certain modification of them (Lakshmi et al., 2009; Totlani et al., 2012). From the literature review we found that the adsorbents manufactured with modification of rice husk are still not applied on the toxic dye CV. Adsorption study of manufactured RHA mediated Z-RHA and CES on CV dye has been done in the present study. CES is a material made from RHA, with embedding the silica contained by RHA with unburnt carbon. Z-RHA is another manufactured material composed of silica, aluminium and oxygen present in RHA. Finally the adsorption performance of CES and Z-RHA to CV dye removal from aqueous solution has been investigated in this study.

Table 1. Properties of $C V$ dye

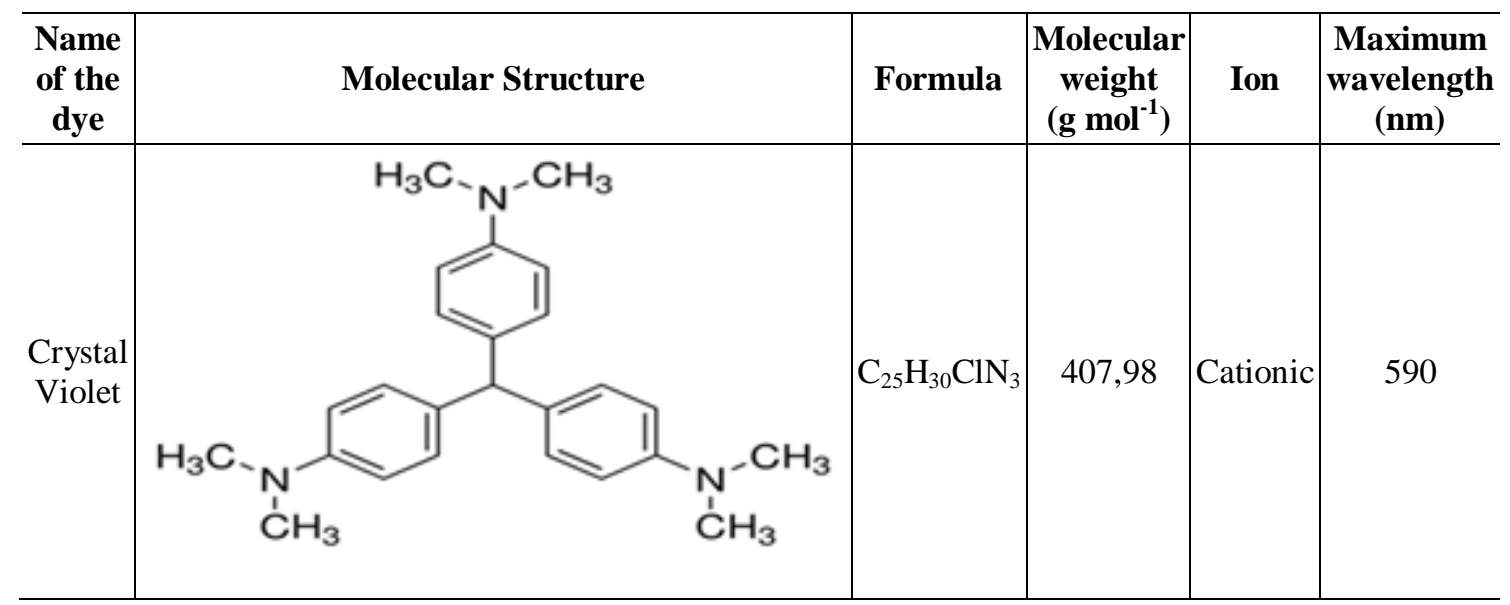




\section{Materials and methods}

\section{Collection of rice husk and preparation of $\mathrm{RHA}$}

Rice husk (RH) sample has been collected from the local market of the Qingdao city in Shandong province of China without any cost. Collected RH sample has been sorted to separate from foreign materials like dust, broken parts of rice shoots and roots, stones etc. followed by sieving and washing under running tap water. Finally, after washing with distilled water the RH sample has been dried in room temperature to remove all the extra moisture present on the surface of the husk. In order to remove the metal impurities the sample has been treated with hydrochloric acid. Then the treated sample has been stirred with sodium hydroxide to remove the excess acid. Concurrently, the treated RH has been thoroughly washed again by distilled water to remove both the acid and the alkali from the surface (Arenas et al., 2017). After drying the rice husk, ash has been produced by pyrolyzing the RH at the temperature from 500 to $700{ }^{\circ} \mathrm{C}$ for $5 \mathrm{~h}$ in a muffle furnace to remove excess organic contents. Consequently, the RHA has been stored in sterile zip-lock bag for further use. Previously, it has been reported that after acid treatment, calcination and pyrolisis of $\mathrm{RH}$, major portion of final material has been represented by silica (Banerjee et al., 2017).

\section{Preparation of Z-RHA}

Zeolite RHA has been prepared from the sodium silicate $\left(\mathrm{Na}_{2} \mathrm{SiO}_{3}\right)$ obtained by RHA. Firstly, seed and feedstock gel have been prepared by mixing RHA with sodium alluminate $\left(\mathrm{NaAlO}_{2}\right)$. A homogeneous seed gel has been prepared by mixing $\mathrm{Na}_{2} \mathrm{SiO}_{3}$ presented in rice husk, with $\mathrm{NaAlO}_{2}$ in distilled water under continuous agitation (Banerjee et al., 2017). Then the prepared gel has been left at ambient temperature up to $24 \mathrm{~h}$ for aging. Consequently, homogeneous gel of $\mathrm{Al}_{2} \mathrm{O}_{3}: 10 \mathrm{SiO}_{2}$ has been formed as seed gel. As well as, feedstock gel has been prepared by following same procedure without any aging. Then the feedstock gel and seed gel have been mixed and stirred vigorously to make a homogeneous mixture and again kept in room temperature for $24 \mathrm{~h}$ for aging. Additionally, the aged solution has been crystallized at $100{ }^{\circ} \mathrm{C}$ for another $24 \mathrm{~h}$ in room temperature. Finally the prepared sample has been washed, dried and stored for further analysis (Goyal et al., 2005).

\section{Preparation of CES}

CES has been prepared from the sodium silicate obtained by RHA, after digestion in the solution of $\mathrm{NaOH}$. RHA has been digested with $\mathrm{NaOH}$ solution for $1 \mathrm{~h}$ at 80 ${ }^{\circ} \mathrm{C}$ temperature to form $\mathrm{Na}_{2} \mathrm{SiO}_{3}$. Then the alkaline solution has been acidified with phosphoric acid $\left(\mathrm{H}_{3} \mathrm{PO}_{4}\right)$ to neutralize the $\mathrm{pH}$ and silicic acid has been formed (Totlani et al., 2012). Silicic acid is a chemical compound of silicon, hydrogen and oxygen, also it is the hydrate of $\mathrm{SiO}_{2}$. Due to heating they lose water to precipitate silica gel as an active form of $\mathrm{SiO}_{2}$. The partially unburnt carbon present in the RHA has been made a duel substrate like CES including mesoporous silica and partially activated carbon (Totlani et al., 2012). Finally, the samples have been kept at $100{ }^{\circ} \mathrm{C}$ for $24 \mathrm{~h}$ and preserved for further analysis. The detailed procedure has been reported previously by Shelke et al. (2010). 


\section{Characterization of adsorbents}

The physico-chemical characteristics of prepared RHA, CES and Z-RHA have been investigated. Gravimetric methods have been used for the proximate analysis. The surface area and the pore size of prepared RHA, CES and Z-RHA have been measured by Brunauer-Emmett-Teller (BET) surface area analyzer. The functional groups present in the adsorbents have been determined by using Fourier transform infrared (FTIR) spectroscopy. To know the structure and orientation of the prepared adsorbents the x-ray diffraction (XRD) analysis has been conducted. The features and the elements present in the prepared adsorbents have been studied by scanning electron microscope (SEM) images and energy dispersive analysis of X-rays (EDX).

\section{Batch kinetic and adsorption studies}

In the adsorption study of CV dye, the $1000 \mathrm{mg} / \mathrm{l}$ dye solution has been prepared by dissolving $1 \mathrm{gm}$ chemical dye in $1000 \mathrm{ml}$ distilled water. Then the stock solution has been used to make different concentrations $(50 \mathrm{mg} / \mathrm{l}, 100 \mathrm{mg} / 1,150 \mathrm{mg} / \mathrm{l}, 200$ $\mathrm{mg} / \mathrm{l}$ ) of dye for further study. $0.5 \mathrm{~g}$ of adsorbent (RHA, CES, Z-RHA) has been added into conical flask with different concentrations of dye solutions (Kumari et al., 2017). Then the flasks have been shaken in a rotary shaker at $30{ }^{\circ} \mathrm{C}$ temperature and $150 \mathrm{rpm}$, and the concentrations have been observed after each $10 \mathrm{~min}$. The $\mathrm{pH}$ of the samples has been adjusted from 2-10 by adding either $0.1 \mathrm{M} \mathrm{HCl}$ or $0.1 \mathrm{M}$ $\mathrm{NaOH}$ solutions. The supernatant liquid has been collected carefully from the flasks by using pipette and the concentrations have been measured by comparing the absorbance from spectrophotometer (Setthaya et al., 2017). The percentages of dye removal, and adsorption capacity at equilibrium phase $\mathrm{q}_{\mathrm{e}}(\mathrm{mg} / \mathrm{g})$ have been calculated as Equation 1 (Langmuir, 1981):

$$
\% \text { Dye Removal }=\frac{\mathrm{Co}-\mathrm{Ce}}{\mathrm{Co}} \times 100
$$

where, $\mathrm{C}_{0}$ denotes initial concentrations and $\mathrm{Ce}$ denotes equilibrium concentrations of CV dye (mg/l). Distilled water has been used to blank before each set of the experiments as control. The adsorption capacity of the unit mass of the adsorbents at equilibrium $\mathrm{q}_{\mathrm{e}}(\mathrm{mg} / \mathrm{g})$ has been calculated by Equation 2 (Langmuir, 1981):

$$
q e=\frac{(\mathrm{Co}-\mathrm{Ce}) \mathrm{V}}{W}
$$

where, $\mathrm{V}$ is the volume of the dye solution $(\mathrm{ml})$ and $\mathrm{W}$ is the weight of the adsorbent (g) added to the volume $\mathrm{V}$.

Each of the experiment has been done three times for the exact and authenticated value of the measured parameters for kinetic and adsorption studies. For the dosage optimization also three replications per each treatment have been used and the average value of data has been plotted. 


\section{Results and discussion}

\section{Characterization of synthesized adsorbents}

\section{FTIR analysis}

The major peaks in the FTIR spectra (Fig. 1) for RHA at $3475 \mathrm{~cm}^{-1}, 2370 \mathrm{~cm}^{-1}$, $1735 \mathrm{~cm}^{-1}, 1143 \mathrm{~cm}^{-1}, 810 \mathrm{~cm}^{-1}$ and $468 \mathrm{~cm}^{-1}$ are representing the presence of the following functional groups $\mathrm{Si}-\mathrm{OH}, \mathrm{O}=\mathrm{C}=\mathrm{O}, \mathrm{C}=\mathrm{O}, \mathrm{Si}-\mathrm{O}-\mathrm{Si}, \mathrm{C}-\mathrm{H}$ and $\mathrm{C}-\mathrm{Cl}$ in the sample (Kumari et al., 2017). On the other hand the FTIR report for CES sample shows the peaks at $3463 \mathrm{~cm}^{-1}, 2881 \mathrm{~cm}^{-1}, 2374 \mathrm{~cm}^{-1}$ representing $\mathrm{Si}-\mathrm{OH}, \mathrm{C}-\mathrm{H}, \mathrm{O}=\mathrm{C}=\mathrm{O}$, have broaden. More peaks at $1604 \mathrm{~cm}^{-1}, 1564 \mathrm{~cm}^{-1}, 1392 \mathrm{~cm}^{-1}, 1118 \mathrm{~cm}^{-1}, 615 \mathrm{~cm}^{-1}$ represent $\mathrm{C}=\mathrm{C}, \mathrm{N}-\mathrm{O}, \mathrm{C}-\mathrm{H}, \mathrm{C}-\mathrm{O}, \mathrm{C}-\mathrm{Cl}$ respectively (Uddin et al., 2009; Chowdhury et al., 2011; Kumari et al., 2017). Whereas the spectra of Z-RHA sample (Fig. 1) show the major peaks at $3363 \mathrm{~cm}^{-1}, 2374 \mathrm{~cm}^{-1}, 2137 \mathrm{~cm}^{-1}, 1666 \mathrm{~cm}^{-1}, 1371 \mathrm{~cm}^{-1}, 887 \mathrm{~cm}^{-1}$ represent Si$\mathrm{OH}, \mathrm{O}=\mathrm{C}=\mathrm{O}, \mathrm{N}=\mathrm{N}=\mathrm{N}, \mathrm{C}=\mathrm{O}, \mathrm{N}-\mathrm{O}, \mathrm{C}-\mathrm{Cl}$ functional groups respectively (Setthaya et al., 2017). The presence of the polar group on the surface of CES and Z-RHA likely gives the cation exchange capacity for both of them.

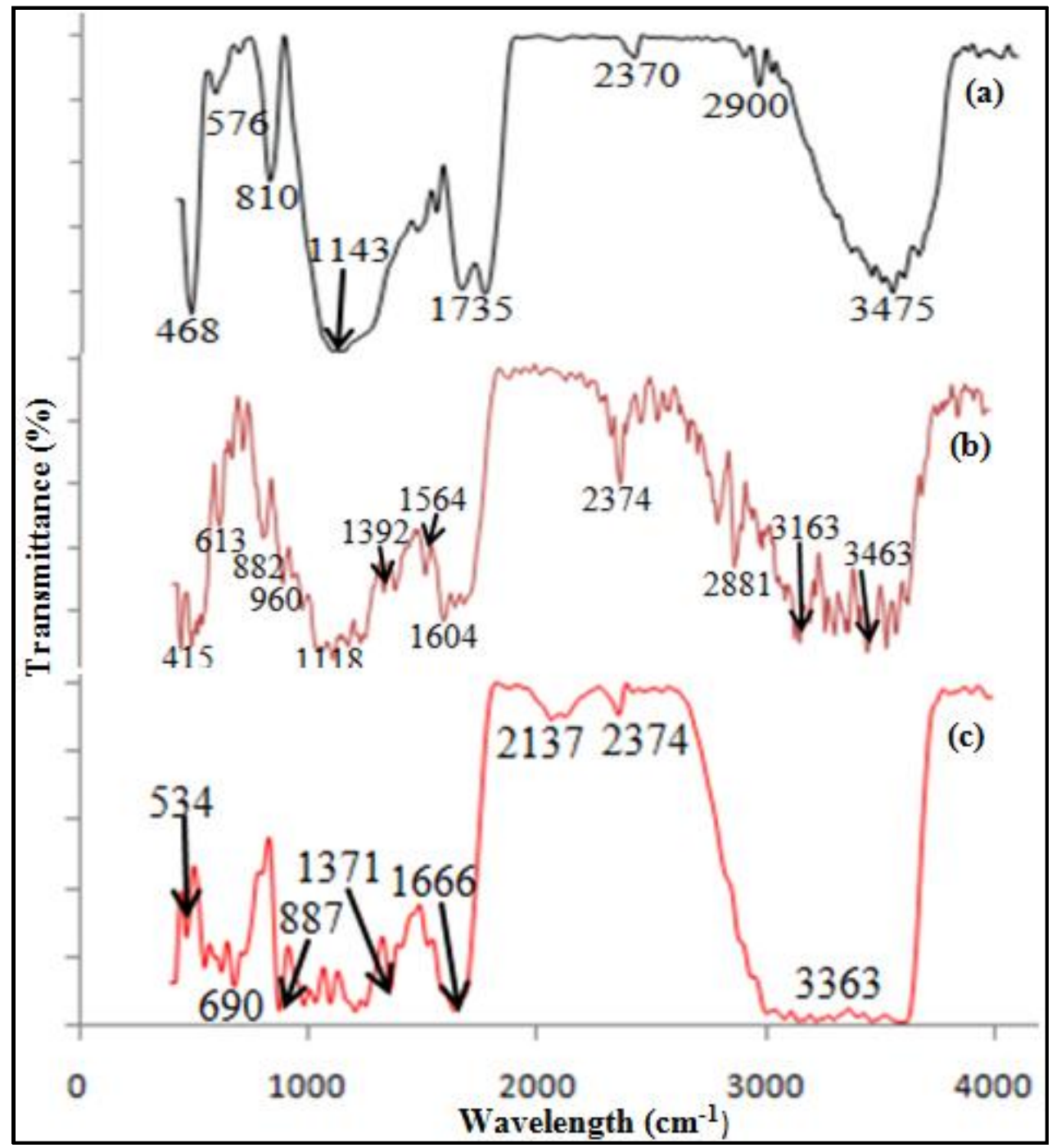

Figure 1. FTIR spectra of (a) RHA (b) CES and (c) Z-RHA 


\section{XRD analysis}

The XRD pattern of the RHA, CES and Z-RHA are shown in Figure $2 a, b$ and $c$ respectively. Both Figure $2 a$ and $b$ show intense peaks at $23 \mathrm{~A}^{\circ}$ which are indicating the presence of carbon in the samples. As well as Figure $2 b$ shows the intense peaks at 33 $\mathrm{A}^{\circ}$ due to the presence of the $\mathrm{SiO}_{2}$ in CES sample (Kumari et al., 2017). Consequently, XRD pattern for Z-RHA sample shows peaks at $25 \mathrm{~A}^{\circ}, 32 \mathrm{~A}^{\circ}$, and $35 \mathrm{~A}^{\circ}$ (Fig. $2 c$ ) indicating the presence of $\mathrm{AlO}_{2}$ and Zeolite $\left(\mathrm{Na}_{2} \mathrm{Al}_{2} \mathrm{Si}_{3} .3 \mathrm{O}_{10} .6\left(\mathrm{H}_{2} \mathrm{O}\right)_{7}\right)$ (Setthaya et al., 2017; Geetha et al., 2015).

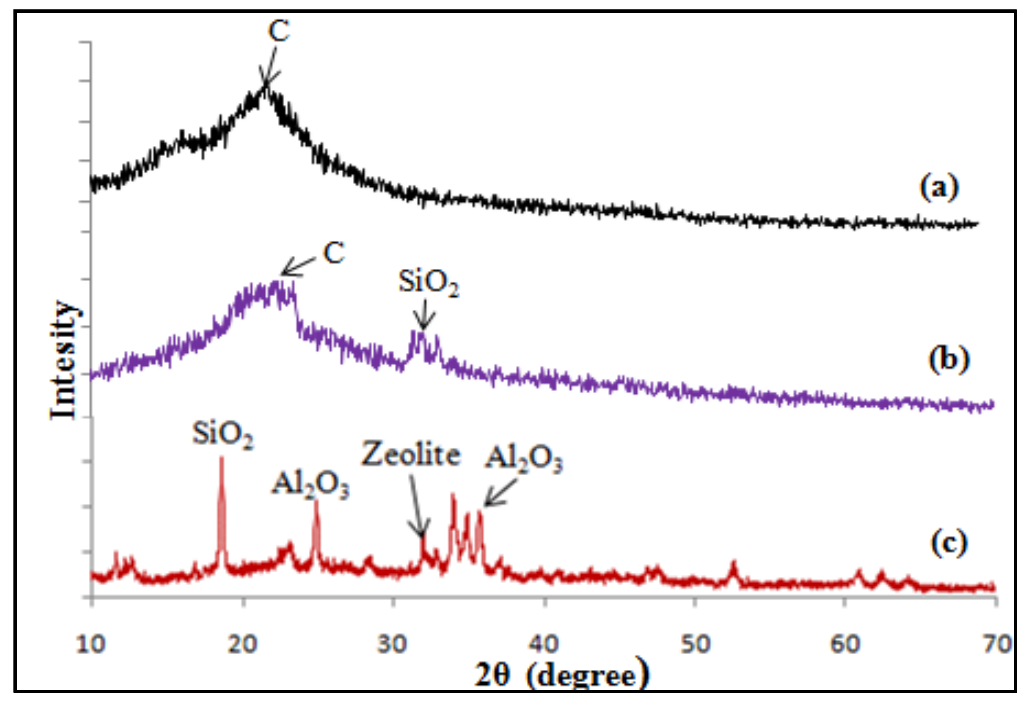

Figure 2. XRD pattern of (a) RHA (b) CES and (c) Z-RHA

\section{SEM and EDX}

Figure $3 a, b$ and $c$ are showing the SEM images of RHA, CES and Z-RHA respectively. Surface structure of the CES and Z-RHA are shown to be more porous than that of the RHA, which is evidence for more adsorption of dyes by CES and ZRHA compared to their parent material, RHA (Setthaya et al., 2017; Geetha et al., 2015). From the Brunauer-Emmett-Teller (BET) analysis it is also found that the surface area of the RHA, CES and Z-RHA is $28 \mathrm{~m}^{2} / \mathrm{g}, 110 \mathrm{~m}^{2} / \mathrm{g}$ and $122 \mathrm{~m}^{2} / \mathrm{g}$ respectively. In EDX analysis of the CES (Fig. 3e) sample shows presence of more amount of silica than the RHA (Fig. 3d). As well as Z-RHA sample (Fig. 3f) shows the presence of $\mathrm{Al}$ which is evidence for the presence of zeolite (Banerjee et al., 2017; Loqman et al., 2017; Lee et al., 2017).

\section{Effect of the initial concentrations}

In this study it has been found that the concentration of the pollutants plays important role in the adsorption of dyes by synthesized adsorbent. Hence, the amount of removal percentages and adsorption capacity of the materials has been tested with different initial concentrations of dyes. The removal percentages of dye by manufactured adsorbents for different concentrations have been calculated by Equation 1 and plotted in Figure 4. Steep increase has been found, maximum removal percentages for CES $(90.69 \%)$ and Z-RHA $(96.45 \%)$ have been noted at the initial concentrations of 100 
$\mathrm{mg} / \mathrm{l}$. Whereas, the maximum removal percentages for RHA $(53.66 \%)$ have been achieved comparatively gradually and found at the initial concentrations of $150 \mathrm{mg} / \mathrm{l}$. Adsorption capacity $(\mathrm{Qe})$ has been measured by Equation 2 and plotted with the initial concentrations of dyes (Fig. 5). Hereby, it shows that the adsorption capacity of the adsorbent depends on the initial concentrations of the adsorbate. The initial concentrations of the adsorbate act as a driving force to be adhered to an adsorbent (Menya et al., 2018; Lee et al., 2017; Li et al., 2014). Due to increasing the amount of the adsorbate concentrations the removal percentages as well as the adsorption capacity of the adsorbent materials increased due to the existing driving force (Lee et al., 2017; Li et al., 2014).

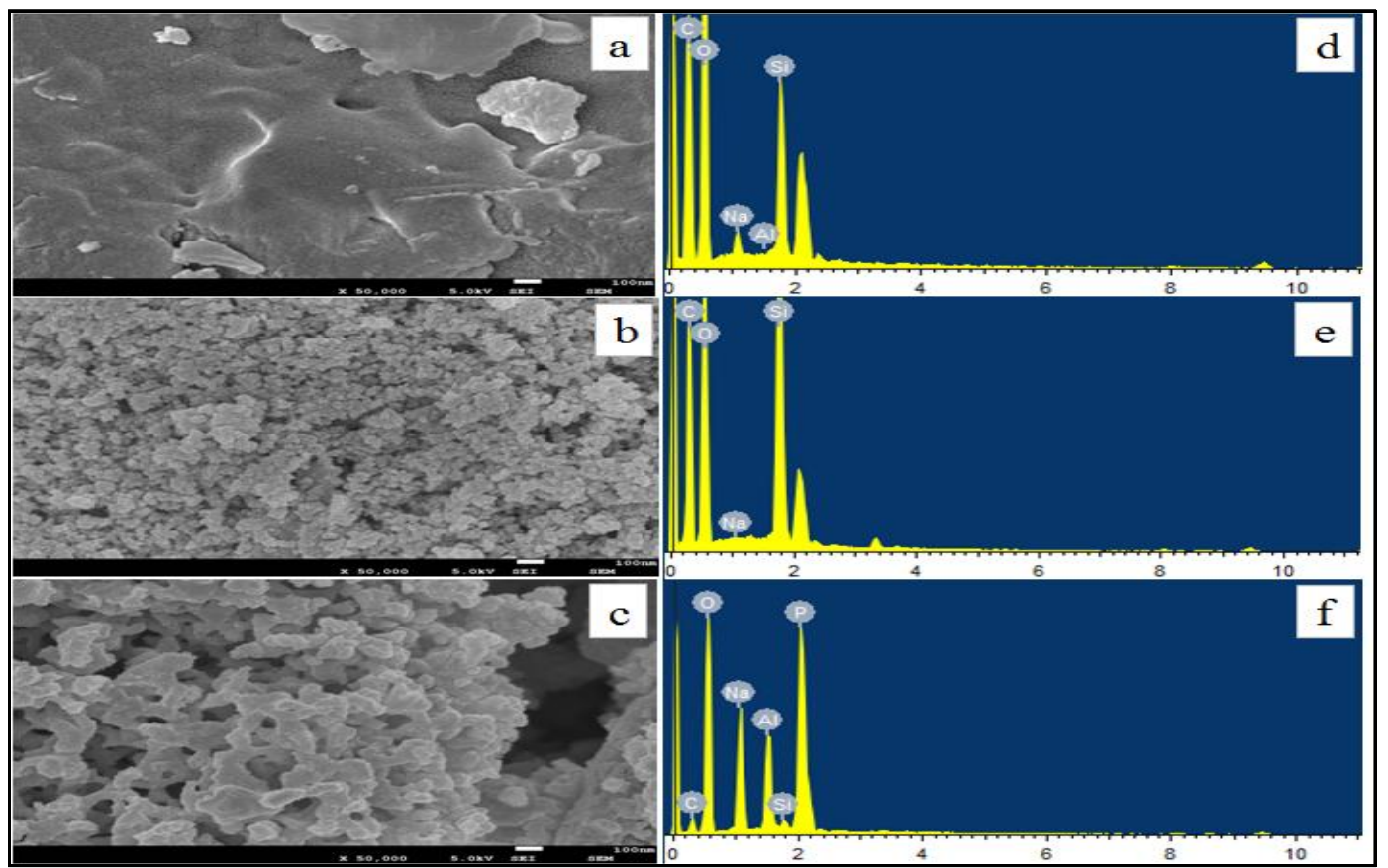

Figure 3. SEM images of (a) RHA (b) CES and (c) Z-RHA and EDX spectra of (d) RHA (e) CES and $(f) Z-R H A$

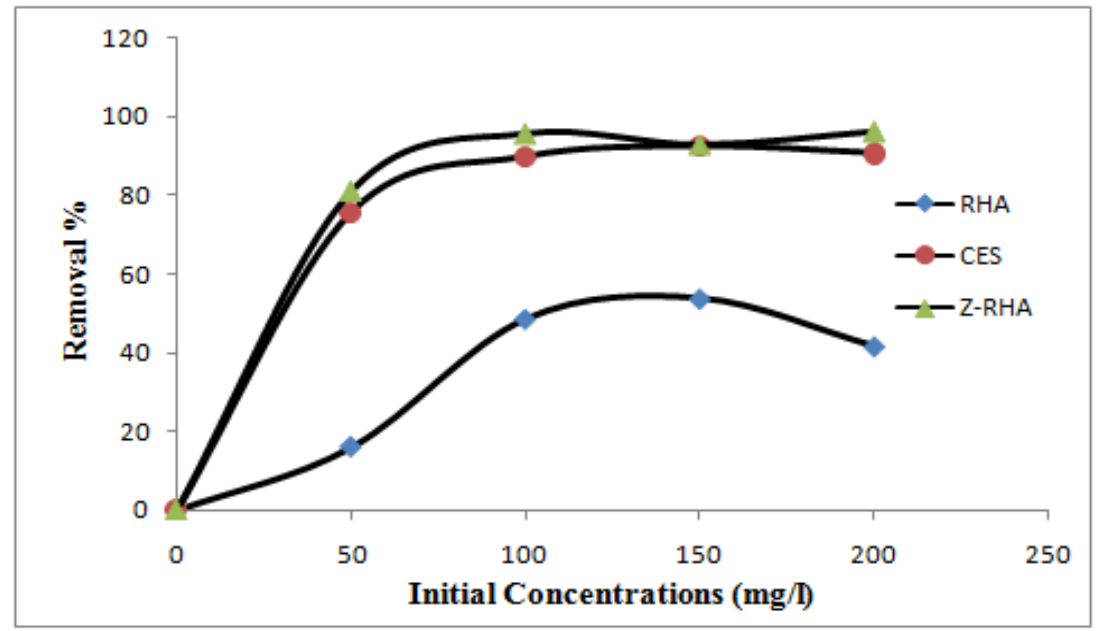

Figure 4. Effect of the initial concentrations on dyes removal 


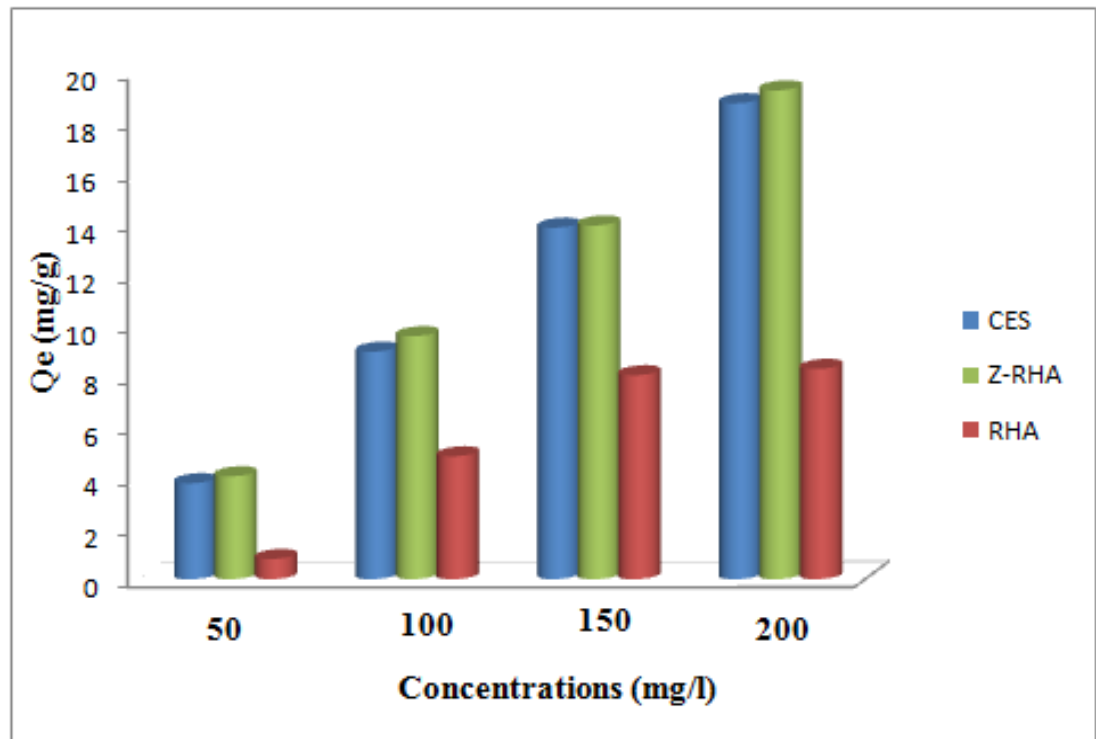

Figure 5. Adsorption capacities of the adsorbents in different concentrations of dyes

The maximum adsorbent capacity for RHA, CES and Z-RHA is $8.3 \mathrm{mg} / \mathrm{g}, 18.78$ $\mathrm{mg} / \mathrm{g}$ and $19.28 \mathrm{mg} / \mathrm{g}$ respectively which values are significantly more reasonable compared to those of other investigations (Table 2). Different studies have investigated the adsorption capacity of RHA and chemical modified RHA on different heavy metals. Adsorption of CES and Z-RHA on dye like CV is a noble approach which has been investigated in this study. However the adsorption capacity of the manufactured adsorbents is very much reasonable in comparison with other published study.

Table 2. Comparative adsorption capacity of different relative adsorbents

\begin{tabular}{c|c|c|c}
\hline Type of adsorbent & Adsorbate & $\begin{array}{c}\text { Adsorption } \\
\text { capacity (mg/g) }\end{array}$ & References \\
\hline Natural modernite (zeolite) & $\mathrm{As}$ & 17.33 & Chutia et al., 2009 \\
Bulgarian natural zeolite & $\mathrm{Cu}$ & 6.74 & Panayatova et al., 2001 \\
Zeolite & $\mathrm{Fe}$ & 3.93 & Ostroski et al., 2009 \\
Rice husk derived zeolite (Z-RHA) & $\mathrm{CV}$ dye & 19.28 & Present study \\
Mesoporous RHA & $\mathrm{Cd}$ & 11.7 & Srivastava et al., 2006 \\
Rice husk & $\mathrm{Hg}$ & 6.7 & Khalid et al., 1999 \\
Rice husk ash & $\mathrm{Pb}$ & 12.3 & Doner and Akman, 2003 \\
RHA & $\mathrm{CV} \mathrm{dye}$ & 8.3 & Present study \\
Carbon embedded silica from RHA (CES) & $\mathrm{CV}$ dye & 18.78 & Present study \\
\hline
\end{tabular}

\section{Effect of $p H$}

The $\mathrm{pH}$ of the adsorbate solution is considered a very important parameter in adsorption studies due to two reasons, namely that hydrogen ions have strong competing ability as well as they can ionize the adsorbent surfaces (Rattanapan et al., 2017; Totlani et al., 2012). The change in solution $\mathrm{pH}$ may cause to dissociate the functional groups present on the surface of the adsorbent which ultimately affects the 
adsorption processes of the adsorbent. The effect of the $\mathrm{pH}$ on dye adsorption using manufactured materials has been studied by varying $\mathrm{pH} 2$ to 10 . The data on the removal percentages of dyes with different $\mathrm{pH}$ of the solutions plotted in Figure 6. It can be concluded that the removal percentages of dyes for CES and Z-RHA show higher removal percentages from the starting up to $\mathrm{pH} 8$, whereas the removal percentage for RHA sample was less at lower $\mathrm{pH}$. These phenomena might happen due to the high surface area of CES and Z-RHA samples rather than the RHA, which may nullify acidic effects during adsorption (Rattanapan et al., 2017; Mor et al., 2016; Totlani et al., 2012).

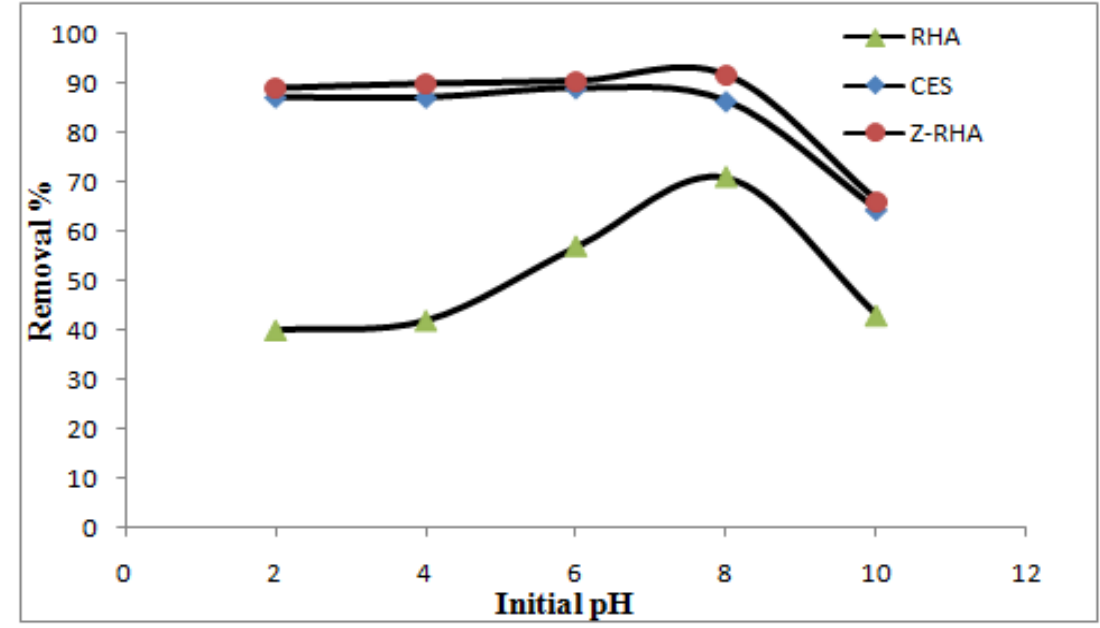

Figure 6. Effect of the initial $p H$ on dyes' removal

\section{Effect of dosages}

The effect of the different dosages on CV dyes' removal has been studied and plotted in Figure 8 between removal percentage against the adsorbent dosage $0.2-1.2 \mathrm{mg} / 50 \mathrm{ml}$. Usually, the adsorption or removal percentages increase with increasing dosages of adsorbents due to large surface area and consequently, more availability of the vacant sites for adsorption (Rattanapan et al., 2017; Totlani et al., 2012). From Figure 7, it is shown that the maximum removal percentages for all materials RHA (62.74\%), CES $(92.24 \%)$ and Z-RHA (94.61\%) are at the dosages $0.6 \mathrm{mg} / 50 \mathrm{ml}$. After that the removal percentages did not increase with the increase of dosages. This might have happened due to the saturation of the adsorbent in the pollutant solutions (Sawasdee et al., 2017; Kumari et al., 2017; Sharma et al., 2010). Finally it can be concluded from Figure 8 that the Z-RHA shows more removal efficiency than the other two due to its large surface area.

\section{Effect of contact time}

The effect of the contact time on CV dye adsorption has been plotted in Figure 8. From Figure 8 it has been revealed that the adsorption capacity for all of three manufactured adsorbents increases steeply within short time $(10 \mathrm{~min})$, and then there is no noticeable increase with time. In this time the adsorption capacities of RHA, CES and Z-RHA are $8.3 \mathrm{mg} / \mathrm{g}, 18.75 \mathrm{mg} / \mathrm{g}$ and $19.28 \mathrm{mg} / \mathrm{g}$ respectively. This result can be explained as, at the initial stages of the adsorption the large number of the vacant places 
are available on the surface of the adsorbents (Yadav et al., 2015; Totlani et al., 2012; $\mathrm{Xu}$ et al., 2009). With the increase of the time a repulsive force also starts between the molecules on the adsorbent surface and the bulk phase which is the reason to stop the further adsorption with more lapse time (Singh et al., 2015; Saravanane et al., 2002). The experiment has been carried up to 70 min but no further changes in adsorption have been noticed.

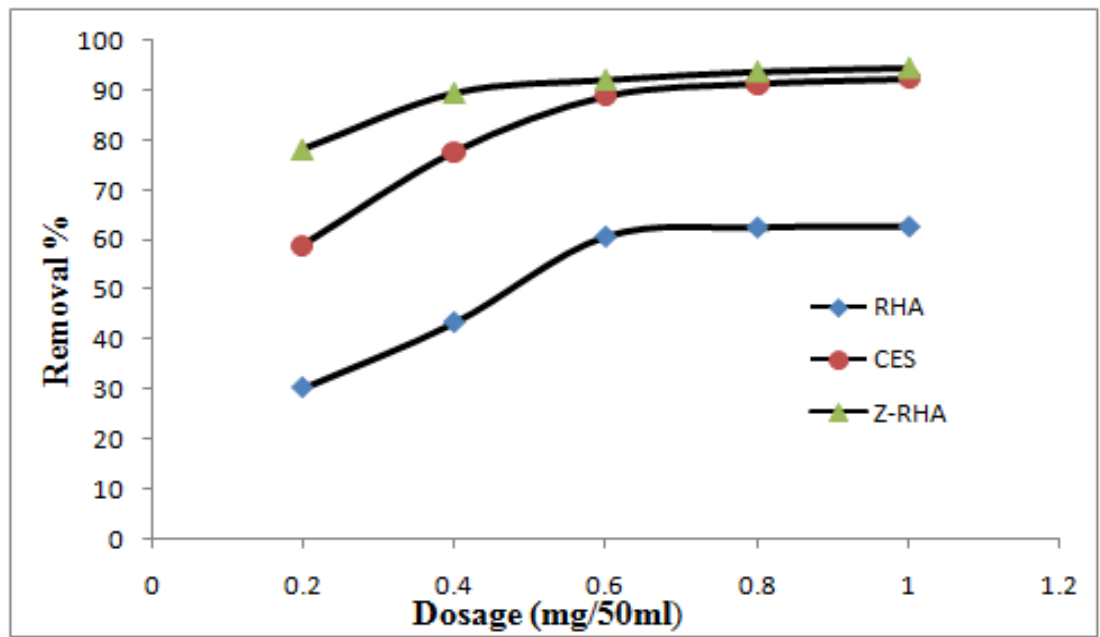

Figure 7. Removal percentages of dyes with different dosages of RHA, CES and Z-RHA

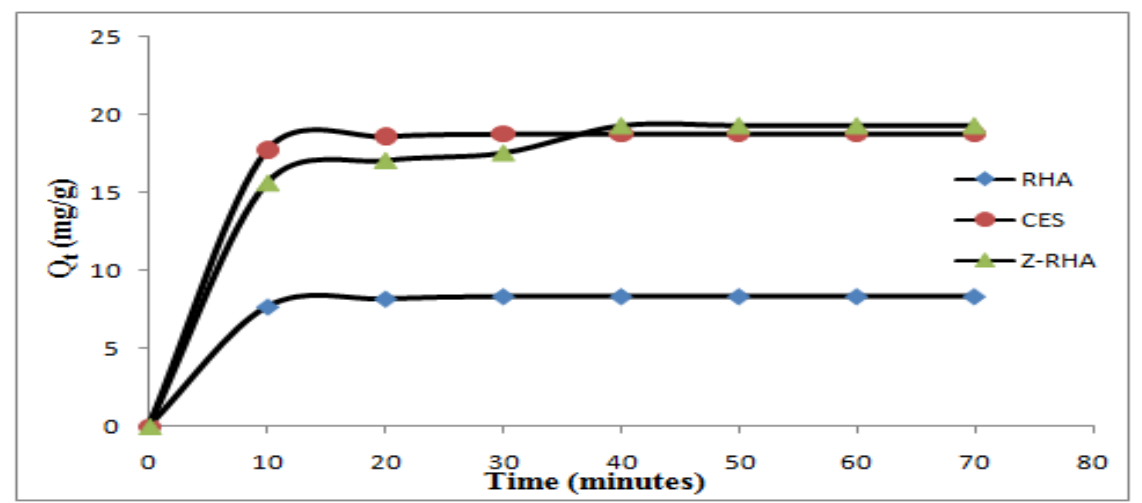

Figure 8. Effect of the contact time on adsorption capacity of the adsorbents

\section{Conclusion}

Rice husk is a common waste which is locally available in large quantity with no price. Chemically modified rice husk ash is basically used by many researchers over the world to decontaminate different kinds of the heavy metals but still there has been a lack of research on removal of textile dyes from aqueous solutions. In this study CES and Z-RHA have been synthesized from RHA after chemical modification and applied to remove $\mathrm{CV}$ dyes from aqueous solution. The percentages of removal of $\mathrm{CV}$ dyes have been found for RHA, CES and Z-RHA are 53.6\%, 90.69\% and $96.45 \%$ respectively. The optimization of adsorption has been studied and maximum adsorption of the adsorbents are found at initial concentration of adsorbate $100 \mathrm{mg} / \mathrm{l}$, solution $\mathrm{pH} 8$, adsorbent dosages $0.6 \mathrm{mg} / 50 \mathrm{ml}$ and contact time $10 \mathrm{~min}$. FTIR and XRD analyses 
indicate the presence of silica and aluminum in the CES and Z-RHA which are evident to synthesis of carbon embedded silica and zeolite. From the SEM images it has been also found that the surface of the CES and Z-RHA samples are more rough than that of their parent materials, which evidently adsorb more pollutants than RHA. Thus, from the result of this study it is clear that the chemically modified rice husk can be an alternate solution to treat textile wastewater. Due to the easy availability of the rice husk it has the opportunity to be more popular adsorbent in water treatment and it can help managing the huge amount of rice husk produced as agro waste over the world. Based on this study it can be recommended for future research to examine if the RHA can be further used to remove both anionic and cationic dyes with more chemical modification. Chemically modified RHA adsorbents can possibly be applied in large scale for industrial wastewater treatment which can be a tonic of research for the future researchers.

Acknowledgements. This work was supported by the State Key Laboratory of Environmental Criteria and Risk Assessment (SKLECRA2013FP12) and the Shandong Province Key Research and Development Program (2016GSF115040). The first author would also like to thanks for the financial support by the Chinese Scholarship Council, China (CSC No: 2016GXYO18).

\section{REFERENCES}

[1] Arenas, C. N., Vasco, A., Betancur, M., Martinez, J. D. (2017): Removal of indigo carmine (IC) from aqueous solution by adsorption through abrasive spherical materials made of rice husk ash (RHA). - Process Safety and Environmental Protection 106: 224238.

[2] Banerjee, S., Barman, S., Halder, G. (2017): Sorptive elucidation of rice husk ash derived synthetic zeolite towards deionization of coalmine waste water: A comparative study. Groundwater for Sustainable Development 5: 137-151.

[3] Chowdhury, S., Chakraborty, S., Saha, P. (2011): Biosorption of Basic Green 4 from aqueous solution by Ananas comosus (pineapple) leaf powder. - Colloids and Surfaces B 84: 520-527.

[4] Chutia, P., Kato, S., Kojima, T., Satokawa, Shigeo (2009): Adsorption of As(V) on surfactant-modified natural zeolites. - Journal of Hazardous Materials 162: 204-211.

[5] Dalaran, M., Emik, S., Güclü, G., Banu, T., Özgümüs, S. (2011): Study on a novel polyampholyte nanocomposite superabsorbent hydrogels: synthesis, characterization and investigation of removal of indigo carmine from aqueous solution. - Desalination 279: 170-182.

[6] Doner, G., Akman, S. (2003): The removal of copper, cadmium and lead by rice husk ash. - Fresenius Environment Bulletin 12: 736-739.

[7] Geetha, P., Latha, M. S., Koshy, M. (2015): Biosorption of malachite green dye from aqueous solution by calcium alginate nanoparticles: Equilibrium study. - Journal of Molecular Liquids 212: 723-730.

[8] Goyal, N., Barman, S., Bulasara, V. K. (2005): Adsorptive removal of Biochanin A, an endocrine disrupting compound, from its aqueous solution by synthesized zeolite NaA. Desalination and Water Treatment 2005: 1-11.

[9] Hao, O. J, Kim, H., Chiang, P. C. (2000): Decolorization of wastewater. - Environmental Science and Technology 30: 449-505.

[10] Khalid, N., Ahmed, S., Kiani, S. N., Ahmed, J. (1999): Removal of mercury from aqueous solutions by adsorption to rice husks. - Separation Science and Technology 34: 3139-3153. 
[11] Kumari, H. J., Krishnamoorthy, P., Arumugam, T. K., Radhakrishnan, S., Vasudevan, D. (2017): An efficient removal of crystal violet dye from waste water by adsorption onto TLAC/Chitosan composite: A novel low cost adsorbent - International Journal of Biological Macromolecules 96: 324-333.

[12] Lakshmi, U. R., Srivastava, V. C., Mall, I. D., Lataye, D. H. (2009): Rice husk ash as an effective adsorbent: evaluation of adsorptive characteristics for indigo carmine dye. Journal of Environmental Management 90: 710-720.

[13] Langmuir, I. (1981): The adsorption of gases on plane surfaces of glass, mica and platinum. - Journal of the American Chemical Society 40: 1361-1403.

[14] Lee, J. H., Kwon, J. H., Lee, J. W., Lee, H., Chang, J. H., Sang, B. I. (2017): Preparation of high purity silica originated from rice husks by chemically removing mettalic impurities. - Journal of Industrial and Engineering Chemistry 50: 79-85.

[15] Li, W., Gong, X., Wang, K., Zhang, X., Fan, W. (2014): Adsorption characteristics of arsenic from micro-polluted water by an innovative coal-based mesoporous activated carbon. - Bioresource Technology 165: 166-173.

[16] Loqman, A., Bali, B. E., Lutzenkirchen, J., Weidler, P. G., Kherbeche, A. (2017): Adsorptive removal of crystal violet dye by a local clay and process optimization by response surface methodology. - Applied Water Science 7: 3649-3660.

[17] Mass, R., Chaudhari, S. (2005): Adsorption and biological decolourization of azo dye Reactive Red-2 in semi continuous anaerobic reactors. - Process Biochemistry 40: 699705 .

[18] Menya, E., Olupot, P. W., Storz, H., Lubwama, M., Kiros, Y. (2018): Production and performance of activated carbon from rice husks for removal of natural organic matter from water. - Chemical Engineering Research and Design 129: 271-296.

[19] Mor, S., Chhoden, K., Ravindra, K. (2016): Application of agro-waste rice husk ash for the removal of phosphate from the wastewater. - Journal of Cleaner Production 129: 673-680.

[20] Naiya, T. K., Bhattacharya, A. K., Mandal, S., Das, S. K. (2009): The sorption of lead (II) ions on rice husk ash. - Journal of Hazardous Materials 163: 1254-1264.

[21] O’Neill, C., Hawkes, F. R., Hawkes, D. L., Lourenco, N. D., Pinheiro, H. M., Delée, W. (1999): Colour in textile effluents-sources, measurement, discharge consents and simulation: a review. - Journal of Chemical Technology and Biotechnology 74: 10091018.

[22] Ostroski, I. C., Barros, M. A. S. D., Silvab, E. A., Dantas, J. H., Arroyo, P. A., Lima, O. C. M. (2009): A comparative study for the ion exchange of Fe(III) and $\mathrm{Zn}$ (II) on zeolite NaY. - Journal of Hazardous Materials 161: 1404-1412.

[23] Panayatova, M. I. (2001): Kinetics and thermodynamic of copper ions removal from wastewater by use of zeolite. - Waste Management 21: 671-676.

[24] Rattanapan, S., Srikram, J., Kongsune, P. (2017): Adsorption of methyl orange on coffee grounds activated carbon. - Energy Procedia 138: 949-954.

[25] Saravanane, R., Sundararajan, T., Sivamurthyreddy, S. (2002): Efficiency of chemically modified low cost adsorbents for the removal of heavy metals from wastewater: a comparative study. - Indian Journal of Environmental Health 44: 78-81.

[26] Sawasdee, S., Jankerd, H., Watcharabundit, P. (2017): Adsorption of dyestuff in household-scale dyeing onto rice husk. - Energy Procedia 138: 1159-1164.

[27] Setthaya, N., Chindaprasirt, P., Yin, S., Pimraksa, K. (2017): TiO2-zeolite photocatalysts made of metakaolin and rice husk ash for removal of methylene blue dye. - Powder Technology 313: 417-426.

[28] Secula, M. S., Cagnon, B., Cretescu, I., Diaconu, M., Petrescu, S. (2011): Removal of an acid dye from aqueous solutions by adsorption on a commercial granular activated carbon: equilibrium, kinetic and thermodynamic study. - Scientific Study and Research 12: $307-322$. 
[29] Sharma, P., Kaur, R., Baskar, C., Chung, W. J. (2010): Removal of methylene blue from aqueous waste using rice husk and rice husk ash. - Desalination 259: 249-257.

[30] Shelke, V. R., Bhagade, S. S., Mandavgane, S. A. (2010): Mesoporous silica from rice husk ash. - Bulletin of Chemical Reaction Engineering and Catalysis 5: 63-67.

[31] Singh, R., Singh, S., Parihar, P., Singh, V. P., Prasad, S. M. (2015): Arsenic contamination, consequences and remediation techniques: A review. - Ecotoxicology and Environmental Safety 112: 247-270.

[32] Srivastava, V. C., Mall, I. D., Mishra, I. M. (2006): Characterization of mesoporous rice husk ash (RHA) and adsorption kinetics of metal ions from aqueous solution onto RHA. - Journal of Hazardous Materials 134: 257-267.

[33] Totlani, K., Mehta, R., Mandavgane, S. A. (2012): Comparative study of adsorption of Ni (II) on RHA and carbon embedded silica obtained from RHA. - Chemical Engineering Journal 181: 376-386.

[34] Uddin, M. T., Rukanuzzaman, M., Khan, M. M. R., Islam, M. A. (2009): Adsorption of methylene blue from aqueous solution by jackfruit (Artocarpus heteropyllus) leaf powder: A fixed-bed column study. - Journal of Environmental Management 90: 3443-3450.

[35] Vakili, M., Rafatullah, M., Salamatinia, B., Abdullah, A. Z., Ibrahim, M. H., Tan, K. B., Gholami, Z., Amouzgar, P. (2014): Application of chitosan and its derivatives as adsorbents for dye removal from water and wastewater: a review. - Carbohydrate Polymers 113: 115-130.

[36] Xu, X., Gao, B., Wang, W., Yue, Q., Wang, Y., Ni, S. (2009): Adsorption of phosphate from aqueous solutions onto modified wheat residue: characteristics, kinetic and column studies. - Colloids and Surfaces B: Biointerfaces 70: 46-52.

[37] Yadanaparthi, S. K., Graybill, D., von Wandruszka, R. (2009): Adsorbents for the removal of arsenic, cadmium, and lead from contaminated waters. - Journal of Hazardous Materials 171: 1-15.

[38] Yadav, D., Kapur, M., Kumar, P., Mondal, M. K. (2015): Adsorptive removal of phosphate from aqueous solution using rice husk and fruit juice residue. - Process Safety and Environmental Protection 94: 402-409.

[39] Zhang, L., Wan, L., Chang, N., Liu, J., Duan, C., Zhou, Q., Wang, X. (2011): Removal of phosphate from water by activated carbon fiber loaded with lanthanum oxide. - Journal of Hazardous Materials 190: 848-855. 